\title{
Structure of Magnesium Chloride Complexes in Ethereal Systems: Computational Comparison of THF and Glymes as Solvents for Magnesium Battery Electrolytes
}

\author{
Jankowski, Piotr; García Lastra, Juan Maria; Vegge, Tejs
}

Published in:

Batteries and Supercaps

Link to article, DOI:

10.1002/batt.202000168

Publication date:

2020

Document Version

Peer reviewed version

Link back to DTU Orbit

Citation (APA):

Jankowski, P., García Lastra, J. M., \& Vegge, T. (2020). Structure of Magnesium Chloride Complexes in Ethereal Systems: Computational Comparison of THF and Glymes as Solvents for Magnesium Battery Electrolytes. Batteries and Supercaps, 3(12), 1350-1359. https://doi.org/10.1002/batt.202000168

\section{General rights}

Copyright and moral rights for the publications made accessible in the public portal are retained by the authors and/or other copyright owners and it is a condition of accessing publications that users recognise and abide by the legal requirements associated with these rights.

- Users may download and print one copy of any publication from the public portal for the purpose of private study or research.

- You may not further distribute the material or use it for any profit-making activity or commercial gain

- You may freely distribute the URL identifying the publication in the public portal 


\section{Batteries}

\section{\& Supercaps}

\section{F Chemistry Europe}

European Chemical Societies Publishing

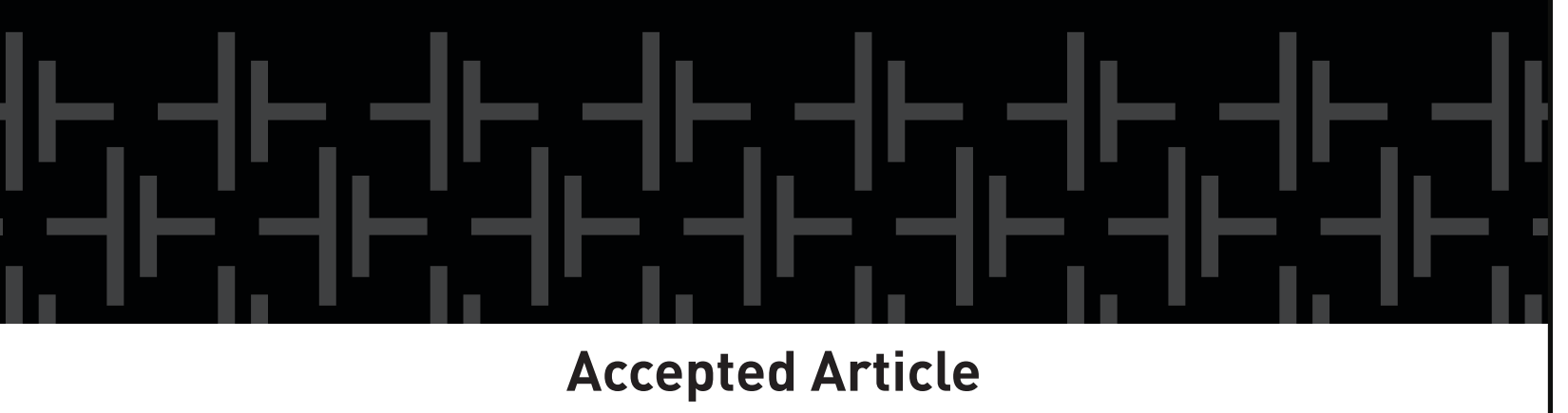

Title: Structure of Magnesium Chloride Complexes in Ethereal

Systems: Computational Comparison of THF and Glymes as

Solvents for Magnesium Battery Electrolytes

Authors: Piotr Jankowski, Juan Maria García Lastra, and Tejs Vegge

This manuscript has been accepted after peer review and appears as an Accepted Article online prior to editing, proofing, and formal publication of the final Version of Record (VoR). This work is currently citable by using the Digital Object Identifier (DOI) given below. The VoR will be published online in Early View as soon as possible and may be different to this Accepted Article as a result of editing. Readers should obtain the VoR from the journal website shown below when it is published to ensure accuracy of information. The authors are responsible for the content of this Accepted Article.

To be cited as: Batteries \& Supercaps 10.1002/batt.202000168

Link to VoR: https://doi.org/10.1002/batt.202000168 


\title{
Structure of Magnesium Chloride Complexes in Ethereal Systems: Computational Comparison of THF and Glymes as Solvents for Magnesium Battery Electrolytes
}

\author{
Piotr Jankowski, ${ }^{\text {aab }}$ Juan Maria García Lastra, ${ }^{a}$ Tejs Vegge ${ }^{\text {a }}$ \\ a Department of Energy Conversion and Storage, Technical University of Denmark, Kgs. Lyngby, \\ Denmark \\ ${ }^{\mathrm{b}}$ Faculty of Chemistry, Warsaw University of Technology, Warsaw, Poland \\ *pioja@dtu.dk
}

\begin{abstract}
The structure of the electrolyte is crucial for the performance of rechargeable magnesium batteries. Doubly charged cations interact much stronger with both anions and solvent molecules, forming different size clusters. Here, we apply DFT calculations to investigate salt solvation by altering the first solvation shell of the magnesium-chloride complexes in different ethereal solvents: tetrahydrofuran, monoglyme, diglyme, triglyme and tetraglyme. The analysis was performed by looking for the most stable structures, considering mono-, di- and trimeric clusters of $\mathrm{Mg}_{x} \mathrm{Cl}_{y}$. The determination of clusters geometries, together with their energies, resulted in a comprehensive picture of the thermodynamically preferred state of the electrolyte, and allowed for a simple assessment of the electrochemical activity of the electrolyte. Our analysis shows that clustering is beneficial for desolvation of magnesium from the cluster, but causes overpotentials due to hindered electron transfer.
\end{abstract}

\section{Introduction}

Magnesium battery technologies bring much promise to the energy storage market, especially regarding high energy density and low production cost. A multivalent nature doubles the capacity obtained for a certain number of ions, reaching a theoretical value of $2205 \mathrm{mAh} \mathrm{g}^{-1}$ for $\mathrm{Mg}$, with more available materials needed to build such a battery. ${ }^{[1-4]}$ Nonetheless, prior to their commercialization, many challenges have to be solved, especially regarding the reversibility of the processes at the electrodes ${ }^{[5]}$ Here, a huge impact of the electrolyte is observed, which can completely preclude plating of magnesium. ${ }^{[6,7]}$ Magnesium battery electrolytes differ significantly from the well-known ones for Liion batteries, causing new challenges in understanding and designing such a system. ${ }^{\left[{ }^{[8]}\right]}$ The high charge density of $\mathrm{Mg}^{2+}$ results in a pronounced tendency to form ion pairs and aggregates. ${ }^{[10]}$ These Mg-complexes usually become the primary charge carriers, and, as the electroactive species, they govern the deposition/dissolution reactions at the electrolyte-electrode interface. Many electrolyte properties depend on the solvation structure of the electrolyte species, e.g., the electrochemical stability is the result of a complicated interplay of interactions in which the component having the lowest stability sets the overall limit. Further, the solvation structure can be very complex, especially as electroactive species with divalent cations frequently contain anions in the first solvation shell. Therefore, the structure of magnesium electrolytes is highly influenced by both the solvent and the salt used. Due to the environmental issues and problems with current collector corrosion, much effort has been placed on the development of $\mathrm{Cl}^{-}$-free electrolytes; ${ }^{[11-14]}$ however, the best performance is still achieved when chlorine anions are included in the system. ${ }^{[7,15-17]}$ Their presence induces $\mathrm{Mg}-\mathrm{Cl}$ bonding structures that are considered to be responsible for the success of the electrode processes. ${ }^{[18]}$ Nonetheless, also solvent molecules play an essential role in creating electrochemically highly active species ${ }^{[19]}$ The choice of solvent is strictly limited by their stability against metallic magnesium, leaving 
ethers as the most commonly employed. ${ }^{[20]}$ Despite their low dielectric constant, ethers work well in dissolving and creating charge carriers, which has recently been explained by the redissociation phenomena. ${ }^{[21]}$ The commonly used tetrahydrofuran (THF) works well with many salts; however, its coordination abilities are limited by the bulkier structure of the ring. Hence, to increase the solubility of Mg-salts multidentate glymes ( $\left.\mathrm{Gn:} \mathrm{CH}_{3} \mathrm{O}-\left(\mathrm{C}_{2} \mathrm{H}_{4} \mathrm{O}-\right)_{n} \mathrm{CH}_{3}\right)$ are widely applied. The flexibility of glymes allows them to wrap tightly around the cations and adopt different conformations, resulting in strong solvating abilities. ${ }^{[22]}$ The properties of the electrolyte are changing with an increase of glyme length, thus higher denticity of the solvent. The shortest, monoglyme (G1), was commonly used many times instead of THF, and did not show problems with desolvation of $\mathrm{Mg}^{2+}$ at the electrode. Also, longer glymes, up to tetraglyme (G4), have been used successfully, although some increase in overpotential is observed. ${ }^{[12,22,23]}$ In general, an increase in glyme length gives a (desired) lower volatility of the electrolyte, but at the cost of higher viscosity and slower transport kinetics. ${ }^{[22,24-26]}$ Undoubtedly, that also affects the induced structure of the complexes and the reached equilibrium, which is crucial for magnesium electrolytes, determining many parameters, including the battery lifetime.

Here, our goal is to provide thermodynamic insight on the solvatation, isomerization, and complexation of possible $\mathrm{Mg}-\mathrm{Cl}$ species in ethereal solvents based on DFT calculations. The structure of THF-based electrolytes has been thoroughly studied before, ${ }^{[27,28]}$ and provides a good starting point for exploring different glycol ethers, which are more suitable for battery application, due to their higher thermal and chemical stabilities. Such a detailed understanding of the solvation behaviour is a prerequisite for developing high-performance electrolytes for magnesium batteries, finally showing how distinct structures formed in diglyme (G2) can enhance the processes at the electrodes.

The paper starts with a discussion of the methodology applied for the studies, followed by a discussion of the results and some final comments provided in the last section.

\section{Methodology}

Calculations of the $\mathrm{Mg}-\mathrm{Cl}$ systems were performed using the Gaussian 16 package. ${ }^{[29]}$ The chemical space of possible configurations of magnesium chloride complexes with solvent was sampled using a representative set of possible geometries selected based on chemical intuition; in total, more than 700 starting geometries were created and tested. To accelerate calculations of such a huge number of structures, all geometries were preoptimized using the PM7 semi-empirical method ${ }^{[30]}$. The full DFT calculations were performed using the $6-311++G(d, p)$ basis set ${ }^{[31]}$ and the M06-2X functional ${ }^{[32]}$, as has been demonstrated to give an excellent agreement with experimental results, especially regarding thermodynamic data (comparison of PBE, B3LYP and M06-2X functionals in Table S5). ${ }^{[27,33]}$ To take into account the strong interactions between the solvent molecules and ionic species, the complexes, which already explicitly contain solvent molecules in the first coordination shell, were placed in an implicit solvent using the SMD model ${ }^{[34]}$ in order to describe the long-range interaction with the solvent from the outer shell. For all of the systems, SMD parameters for THF were used (dielectric constant, $\varepsilon=7.4257$ ), as all studied ethers have $\varepsilon$ in the range $7.4 \pm 0.3 .{ }^{[35]}$ For each optimized structure, frequency calculations were performed to confirm the true minima, as well as to obtain the thermodynamic contributions to the Gibbs free energies. All energies of formation, referred in the paper as free energies, were calculated based on the DFT-obtained Gibbs free energies according to the equation:

$$
\Delta G_{\text {formation }}=G_{\text {complex }}-\left(\mathrm{n}_{M g^{2+}} \cdot G_{M g^{2+}}+\mathrm{n}_{C l^{-}} \cdot G_{C l^{-}}+\mathrm{n}_{s} \cdot \mu_{s}\right)
$$

where $G_{\mathrm{x}}$ is the Gibbs free energy of species X (complex, $\mathrm{Mg}^{2+}$ or $\mathrm{Cl}^{-}$ion) and $\mu_{\mathrm{s}}$ is the chemical potential of a solvent molecule. Based on that, the bonding free energies were also calculated, as a difference in free energies when increasing number of oxygen atoms $(z)$ in the coordination shell by one: 
bonding free energy $=\Delta G_{\text {formation }}\left(\operatorname{complex}_{z+1}\right)-\Delta G_{\text {formation }}\left(\operatorname{complex}_{z}\right)$

To sufficiently account for solvent-solvent interactions during the transfer of solvent molecules from bulk to the complex, $\mu_{\mathrm{s}}$ was calculated from a cluster of several (3-6) solvent molecules as follow: (i) clusters were generated in a random way by inserting subsequent solvent molecules close to the center of the system, but keeping the minimal distance between molecules equal to $2 \AA$, (ii) the structure was preoptimized using PM7 semi-empirical method to provide sensible starting configurations for the geometry, (iii) a DFT geometry optimization at lower basis set (M06-2X/6$31+G(d)$ ) was performed to get geometry close to the energy minimum, (iv) a final geometry optimization at M06-2X/6-311++G(d,p) was performed with a frequency calculation. In order to account for the error related to the "random" starting geometry, the procedure was performed 10 times for each of the solvents (Table S1). The average energies of the 10 geometries divided by the number of molecules was taken as the chemical potential of a single solvent molecule. For comparison of the clusters with different charge, the free energy of the acceptance of $\mathrm{Cl}^{-}$by strong acid processes was assessed using $\mathrm{AlCl}_{3}$ as a model example molecule, creating $\mathrm{AlCl}_{4}{ }^{-} \cdot{ }^{[28]}$

The assessment of the activity of the clusters at the electrode was performed using two descriptors. To obtain the desolvation energy, one magnesium cation was removed from the cluster and the structure was relaxed. The Gibbs free energy of such obtained geometry was used to determine desolvation energy as follow:

$$
\text { desolvation energy }=G_{\text {complex without } M g^{2+}}+G_{\mathrm{Mg}^{2+}}-G_{\text {initial complex }}
$$

where $G_{\mathrm{x}}$ is the Gibbs free energy of the relaxed species $\mathrm{X}$ (complex, $\mathrm{Mg}^{2+}$ ) in an implicit solvent using the SMD model as discussed above. The reduction potentials were calculated according to an adiabatic thermodynamic cycle, ${ }^{[33]}$ whereafter a correction of $+2.14 \mathrm{~V}$ was used to change the absolute potentials toward the $\mathrm{Mg}^{2+} / \mathrm{Mg}^{\circ}$ scale. ${ }^{[36]}$ The reduced form of the complexes was created by adding one electron to each of the clusters, generating situation when one of the magnesium cations is reduced from $\mathrm{Mg}^{2+}$ to $\mathrm{Mg}^{+}$. Due to problems with SCF convergency of the reduced form using the SMD model, the calculations of reduction potentials were performed using the $\mathrm{C}-\mathrm{PCM}^{[37]}$ solvation model with the same solvent parameters. For that, both the starting and the reduced form were reoptimized, using the optimized SMD structure as an input geometry, and the reduction potentials were determined according to equation, where $\mathrm{F}$ is the Faraday constant:

$$
E_{\text {red }}(V \text { vs. Mg })=\frac{-\left[G_{\text {red }}-G_{\text {start }}\right]}{\mathrm{F}}-[+2.14]
$$

\section{Results and Discussion}

To provide a systematic analysis of the formation of the magnesium chloride complexes in ethereal systems, we analyzed four different glymes that are common in battery research: monoglyme (G1), diglyme (G2), triglyme (G3) and tetraglyme (G4); and compared them to a THF-based reference system, considered as state-of-art solvent for magnesium electrolytes. The analysis was performed by first looking at the complexes, which only contain one magnesium cation. The insight gained from the simplest examples was then used to go forward to more complicated complexes, comprising multiple magnesium cations. That gave us a comprehensive picture of the thermodynamically preferred state of the electrolyte. Finally, the impact of the structure of the most stable complexes on the electrode reaction was examined to establish a relationship connecting the solvent properties with the electrochemical activity of the electrolyte. 


\section{Solvation chemistry of single magnesium clusters}

Monomeric complexes of magnesium can be described as a magnesium ion, $\mathrm{Mg}^{2+}$, coordinated by anions, here $\mathrm{Cl}^{-}$, and solvent molecules to fill the coordination sphere. In magnesium-chloride electrolytes, charge carriers are usually formed by the reaction of $\mathrm{MgCl}_{2}$ with a strong acid that coordinates extra anions forming a negatively charged complex, e.g. $\mathrm{AlCl}_{4}$. Thus, only neutral and positively charged species are considered to be formed by $\mathrm{Mg}^{2+}$, with the number of anions equal to 2,1 and 0 . The rest of the coordination sites are occupied by solvent molecules, leaving space for the formation of a plethora of possible complexes. In the literature, there is some uncertainty regarding the total coordination number of magnesium in the electrolyte. Combined diffraction and spectroscopic efforts mostly indicate that the coordination number (CN) is 6 both for THF ${ }^{[38-48]}$ and glyme ${ }^{[14,22,49-52]}$ systems. Lower $\mathrm{CN}$ complexes have also been reported, but mainly based on mass spectroscopy measurements and suggested to be generated during the ionization process. ${ }^{[53,54]}$

An alternative approach to study solvation structures is using first principle calculations. Moss et al. employed DFT calculations on the Mg-Cl-THF system, ${ }^{[27]}$ showing a preferred octahedral coordination for most species except $\mathrm{MgCl}$ (which coordinates only to 3 solvent molecules), in contrast to what is found by spectroscopy ${ }^{[45]}$. Other studies by Wan et al. ${ }^{[55]}$ and Canepa et al. ${ }^{[28]}$ indicate even smaller complexes with $\mathrm{CN}$ equal to 5 and 4, respectively. The correct prediction of the size of the complex seems to be crucial. Thus we adopted our methodology to probe the coordination of $\mathrm{Mg}^{2+}$ with different initial geometries: starting from zero chloride anions, up to two, and stepwise introducing ethereal oxygens to the solvation shell. Figure 1 shows the energetic profile of the free energies as a function of the solvent coordination (left axis), and the binding free energies of subsequent solvent oxygen atoms in the first coordination shell (right axis). Each minimum represents the most stable solvated structure (their corresponding geometries are shown in Figures S1-S3). Starting with the coordination of $\mathrm{Mg}^{2+}$, our results indicate the most stable structure for 6-fold coordination for all studied solvents. The difference between the coordination strength of THF and glymes is observed, with all THF complexes having lower energies. That is related to the conformation change occurring in case of glymes, with the high energy conformation needed to be adapted in order to coordinate the magnesium cation by the neighbouring oxygen atoms. ${ }^{[56,57]}$ The energy of the $\mathrm{Mg}(\mathrm{THF})_{6}{ }^{2+}$ complex reaches $-574 \mathrm{~kJ} \mathrm{~mol}^{-1}$, whereas all glymes show similar trends with energies down to $-519 \pm 7 \mathrm{~kJ} \mathrm{~mol}^{-1}$ for a 6 -fold coordination (Figure 1a). Further increase in coordination number is unfavourable, remarkably for THF. For the glymes the bonding free energy increases with their length - making it less unstable. Similar tendencies are observed when introducing chlorine anions in the coordination shell: both for $\mathrm{MgCl}^{+}$and $\mathrm{MgCl}_{2}{ }^{0}$, THF stabilizes the complexes better by creating octahedral complexes. The energetic cost of further increasing the $\mathrm{CN}$ is however much lower, resulting in a slightly preferred 6fold coordination in case of the short glymes $(G 1, G 2)$ and 7-fold coordination for longer glymes (G3, $\mathrm{G4}$ ), by up to $17 \mathrm{~kJ} \mathrm{~mol}^{-1}$ (Figure $1 \mathrm{~b}$ and $1 \mathrm{c}$ ). Indeed, the occurrence of such high $\mathrm{CN}$ was already observed experimentally for the tetraglyme system, ${ }^{[58,59]}$ and its formation can be explained by analyzing two factors: i) increase in the glyme chain length and ii) the presence of a small $\mathrm{Cl}^{-}$ligand. Looking into the details of the bonding energy of subsequent oxygen atoms, it is visible that for glymes, the observed relationship is not monotonically decreasing. Chelate effect facilitates the coordination of subsequent oxygen atoms from the same chain, introducing some periodic relationship and preference of full coordination of the solvent. This effect is the most visible in the case of $\mathrm{G} 1$ - the second oxygens from the same molecule are bonded $\sim 20 \mathrm{~kJ} \mathrm{~mol}^{-1}$ stronger - but also present and significant in longer glymes, enhancing higher coordination numbers. For an easier observation of the effect, the number of molecules employed in each of the coordination were marked in Figure 1 . The other important factor is the steric hindrance that limits access to the magnesium cation, especially important for bulky solvent as THF, making it less preferable to get extra ligand coordinated. The 
presence of small anions, like $\mathrm{Cl}^{-}$, in the coordination shell reduces the steric hindrance, providing more space for the solvent molecules. That explains why $\mathrm{CN}=7$ is only expected in the case of $\mathrm{MgCl}^{+}$and $\mathrm{MgCl}_{2}$ complexes. In general, the coordination of a higher number of ligands results in a more loose structure. Figure 2 shows a comparison of the $\mathrm{Mg}\left(\mathrm{G}_{4}\right) \mathrm{Cl}_{2}$ stucture with $\mathrm{CN}$ equal 6 and 7 , with the latter stabilized by $19 \mathrm{~kJ} \mathrm{~mol}^{-1}$. The changes in distance between the magnesium cation and the oxygen atoms can be noticed, with an increase of about $0.1 \AA$.

It should be noted that the liquid electrolyte dynamics usually lowers the effective coordination number. This study shows the most stable structures at $\mathrm{OK}$, which establishes the points between which the system is oscillating, and weakly bonded ligands will easily undergo desolvation/solvation reactions.
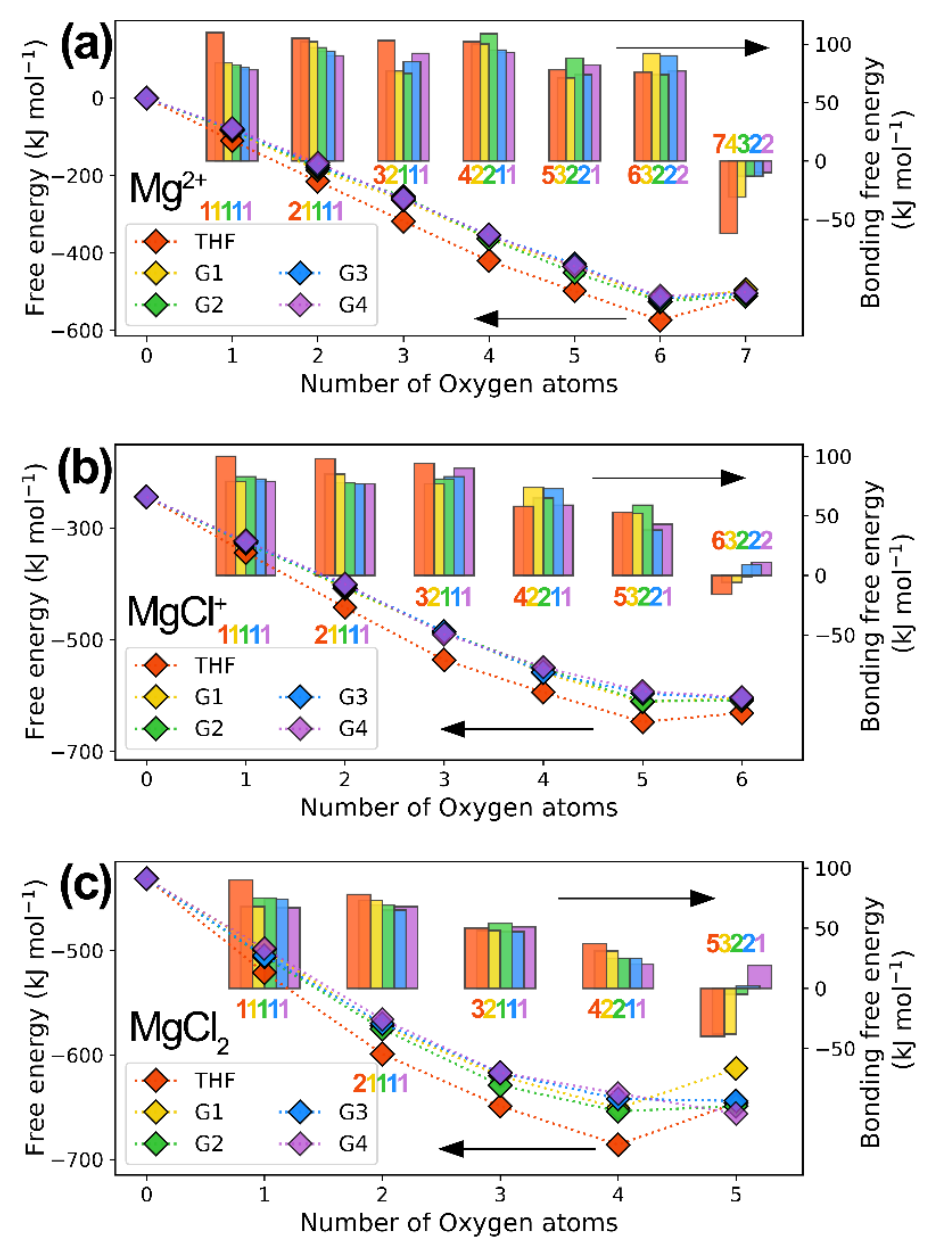

Figure 1. The free energies of formation for magnesium-chlorine complexes in different solvents as a function of the number of oxygen atoms coordinating to $\mathrm{Mg}^{2+}(a), \mathrm{MgCl}^{+}(b)$ and $\mathrm{MgCl}_{2}(c)$; digits indicate number of solvent molecules employed. 

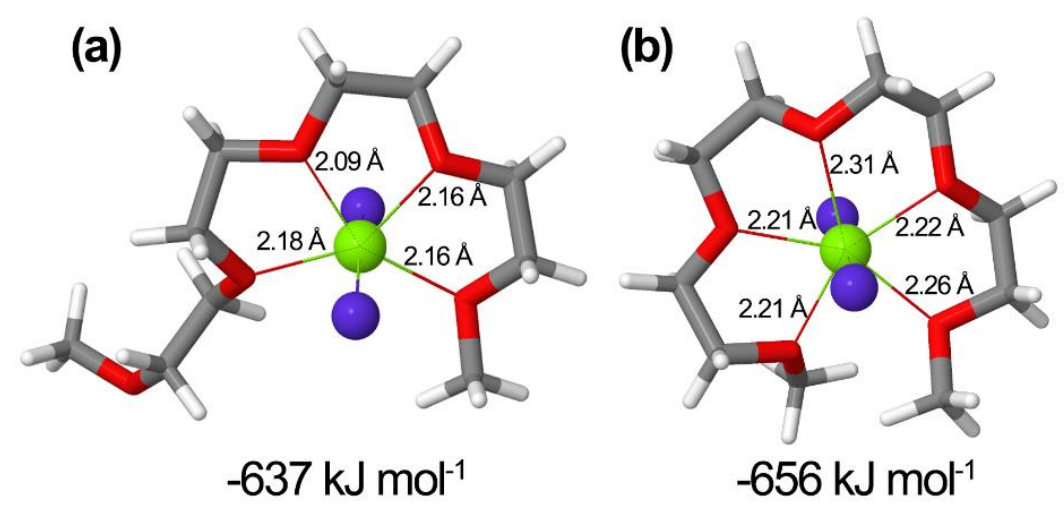

Figure 2. Comparison of two conformations of $\mathrm{MgCl}_{2}(\mathrm{G} 4)_{1}$ and their formation energies; colors describe different elements: green-magnesium, violet - chlorine, red-oxygen, grey-carbon, white-hydrogen.

\section{Formation of multi-magnesium clusters}

Having established the solvation behaviour of ethereal solvents toward magnesium, we can move to higher aggregates that are believed to be crucial for magnesium deposition. ${ }^{[60]}$ Many different stoichiometries of $\mathrm{Mg}_{x} \mathrm{Cl}_{y}$ clusters are possible. However, due to the $\mathrm{N}^{4}$ scaling in the cost of hybrid DFT calculations with size of the system, only the smallest, with 2 and 3 magnesium atoms, are considered here. Four stoichiometries were selected, which represent both mono- and dicationic species: $\mathrm{Mg}_{2} \mathrm{Cl}_{2}{ }^{2+}, \mathrm{Mg}_{2} \mathrm{Cl}_{3}{ }^{+}, \mathrm{Mg}_{3} \mathrm{Cl}_{4}{ }^{2+}$, and $\mathrm{Mg}_{3} \mathrm{Cl}_{5}{ }^{+}$. Furthermore, with an increase in the cluster size, more complex structures are possible, representing basically one of two arrangements, either their mixed combination, namely: i) linear - neighbouring magnesium cations linked by one chlorine ligand or ii) pyramidal - a few chlorine ligands parallelly linking the same magnesium cations. Figure 3 shows the different arrangements considered for $\mathrm{Mg}_{2} \mathrm{Cl}_{3}{ }^{+}$, for which basic DFT calculations with implicit solvent (electric field of solvent) show preference toward the pyramidal structures: $-686 \mathrm{vs} .-738 \mathrm{~kJ} \mathrm{~mol}^{-1}$ for linear and pyramidal $\mathrm{Mg}_{2} \mathrm{Cl}_{3}{ }^{+}$structures, respectively. Such a difference can be easily explained as the latter provides a more balanced structure with more occupied coordination sites of magnesium. Thus, explicit solvent-filling in the free coordination sites seems to play a crucial role in favouring some of the arrangements. The proper determination of the structures formed in a specific solvent requires exploration of chemical space that covers all possible structures, including different $\mathrm{Mg}-\mathrm{Cl}$ and solvent arrangements. For that, only the initial structures with magnesium $\mathrm{CN}>4$ were tested, and for the THFbased system, DFT results show a sustained preference of pyramidal-type conformation for all four stoichiometries (Figure 4). In more detail, for all of them, magnesium show $\mathrm{CN}=6$, as observed in the single magnesium clusters, and maximizes the possible number of chlorine atoms in a coordination shell of all magnesium cations - thereby minimizing the number of solvent molecules in the structure. That is expectedly the result of the bulky structure of the solvent, with steric hindrance as a driving force for that. As a result, complexes: $\mathrm{Mg}_{2} \mathrm{Cl}_{2}(\mathrm{THF})_{8}{ }^{2+}\left(-1138 \mathrm{~kJ} \mathrm{~mol}^{-1} ; 2 \mathrm{x}-578 \mathrm{~kJ} \mathrm{~mol}^{-1}\right), \mathrm{Mg}_{2} \mathrm{Cl}_{3}(\mathrm{THF})_{6}{ }^{+}(-$ $\left.1250 \mathrm{~kJ} \mathrm{~mol}^{-1} ; 2 \mathrm{x}-625 \mathrm{~kJ} \mathrm{~mol}^{-1}\right), \mathrm{Mg}_{3} \mathrm{Cl}_{4}(\mathrm{THF})_{9}{ }^{2+}\left(-1706 \mathrm{~kJ} \mathrm{~mol}^{-1} ; 3 \mathrm{x}-569 \mathrm{~kJ} \mathrm{~mol}^{-1}\right)$ and $\mathrm{Mg}_{3} \mathrm{Cl}_{5}(\mathrm{THF})_{6}{ }^{+}(-$ $1787 \mathrm{~kJ} \mathrm{~mol}^{-1} ; 3 x-596 \mathrm{~kJ} \mathrm{~mol}^{-1}$ ) are predicted to be formed, which agrees well with the available experimental ${ }^{[38-41,43]}$ and computational ${ }^{[27,28]}$ data, primarily reporting $\mathrm{Mg}_{2} \mathrm{Cl}_{3}(\mathrm{THF})_{6}{ }^{+}$and $\mathrm{Mg}_{3} \mathrm{Cl}_{5}(\mathrm{THF})_{6}{ }^{+}$ as active species. Looking at the free energies, the increase in cluster size is not favourable, and larger aggregates are rather a result of the equilibrium with more stable single magnesium clusters $\left.\left(\mathrm{Mg}(\mathrm{THF})_{6}{ }^{2+}:-574 \mathrm{~kJ} \mathrm{~mol}^{-1} ; \mathrm{MgCl}^{\mathrm{THF}}\right)_{5}^{+}:-647 \mathrm{~kJ} \mathrm{~mol}^{-1}\right)$. Additionally, the formation of positive charge carriers is shown to be not energetically preferred, being the most stable the neutral complex $\left(\mathrm{MgCl}_{2}(\mathrm{THF})_{4}\right.$ : $\left.-686 \mathrm{~kJ} \mathrm{~mol}^{-1}\right)$, followed by mono- and then dicationic complexes. That underlines the importance of the strong acidic compounds used to extract chlorine anions and shift equilibrium toward the formation of charge carriers. 
(a)

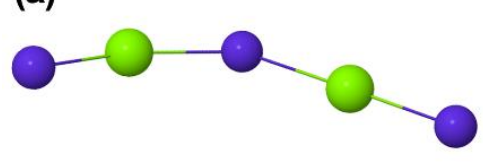

$-686 \mathrm{~kJ} \mathrm{~mol}^{-1}$ (b)

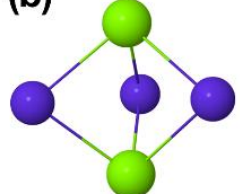

$-738 \mathrm{~kJ} \mathrm{~mol}^{-1}$

Figure 3. Two possible arangements of a $\mathrm{Mg}_{2} \mathrm{Cl}_{3}$ structure and their formation energies; colors describe different elements: green-magnesium.
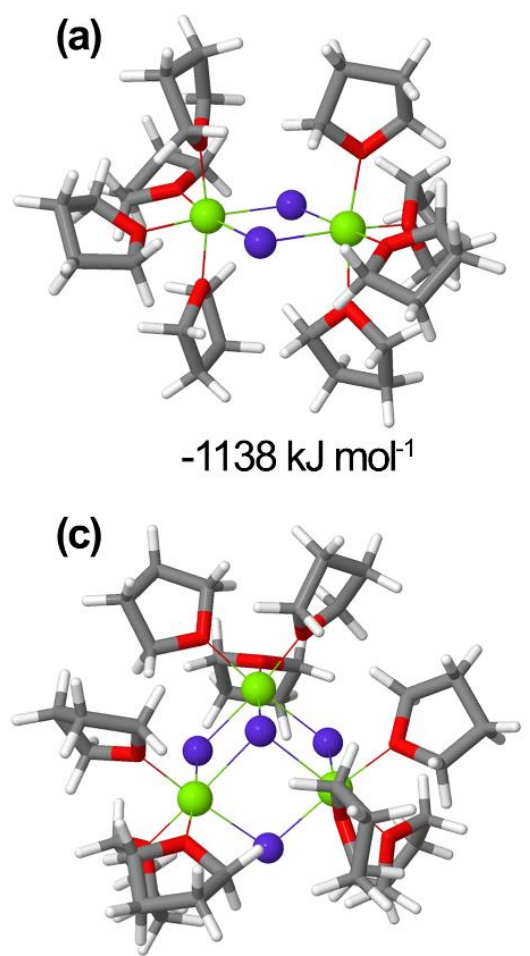

$-1706 \mathrm{~kJ} \mathrm{~mol}^{-1}$

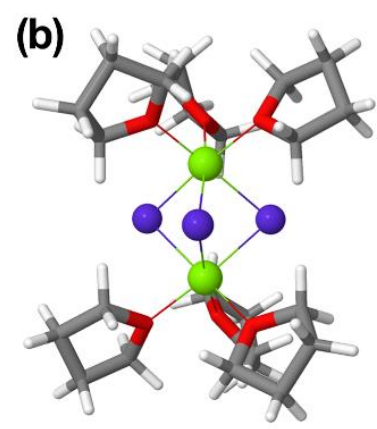

$-1250 \mathrm{~kJ} \mathrm{~mol}^{-1}$

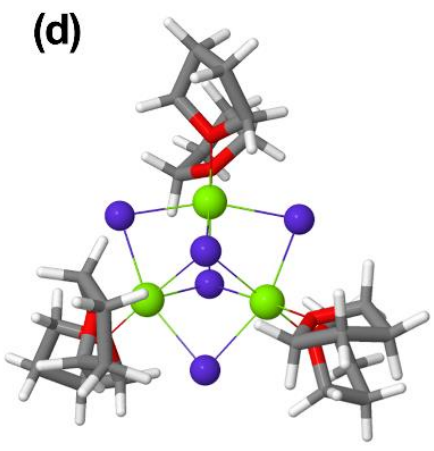

$-1787 \mathrm{~kJ} \mathrm{~mol}^{-1}$

Figure 4. The most stable structures found for THF-based system and their formation energies: $\mathrm{Mg}_{2} \mathrm{Cl}_{2}(\mathrm{THF})_{8}{ }^{2+}(a)$, $\mathrm{Mg}_{2} \mathrm{Cl}_{3}(\mathrm{THF})_{6}{ }^{+}(\mathrm{b}), \mathrm{Mg}_{3} \mathrm{Cl}_{4}(\mathrm{THF})_{9}{ }^{2+}(\mathrm{c}), \mathrm{Mg}_{3} \mathrm{Cl}_{5}(\mathrm{THF})_{6}{ }^{+}(\mathrm{d})$; colors describe the different elements: green - magnesium, violet chlorine, red-oxygen, grey - carbon, white - hydrogen

Moving to the glyme ethers, some alteration of the clusters formed is observed, related to the different characteristics of the solvent. Starting with G1, it can be described as a small, flexible molecule able to provide up to 2 coordination sites for magnesium. All of that results in much less space used per site, which has enormous consequences on the structures formed: the system is no longer determined to minimize the energy by limiting the number of solvent molecules, and more solvated structures are preferred. Also, a chelate effect plays an important role, described in more detail in the previous section, which gave some preference to structures where all coordination sites of the solvent are used. That results in a lower energy of the clusters, where, in case of $\mathrm{G1}$, two or four oxygen atoms are coordinated to magnesium. Thus, for $\mathrm{Mg}_{2} \mathrm{Cl}_{2}(\mathrm{THF})_{4}{ }^{2+}$ four THF molecules are replaced by two $\mathrm{G} 1$ chains giving a rise to a structure similar to $\mathrm{Mg}_{2} \mathrm{Cl}_{2}(\mathrm{G1})_{4}{ }^{2+}\left(-1148 \mathrm{~kJ} \mathrm{~mol}^{-1} ; 2 \mathrm{x}-574 \mathrm{~kJ} \mathrm{~mol}^{-1}-\right.$ Figure S4a). Such a structure agrees with that obtained from XRD experiments. ${ }^{[22]}$ However, the same strategy for $\mathrm{Mg}_{2} \mathrm{Cl}_{3}{ }^{+}$ does not result in a low-energy complex: the pyramidal structure of $\mathrm{Mg}_{2} \mathrm{Cl}_{3}(\mathrm{G} 1)_{4}{ }^{+}\left(-1177 \mathrm{~kJ} \mathrm{~mol}^{-1} ; 2 \mathrm{x}-\right.$ $589 \mathrm{~kJ} \mathrm{~mol}^{-1}$ ) leaves two oxygen atoms free, increasing the free energy (Figure 5a). Attempts to coordinate an extra oxygen atom (possible under dynamic conditions) results in a breaking of the structure and the formation of asymmetric clusters $\left(\mathrm{Mg}_{2} \mathrm{Cl}_{3}(\mathrm{G} 1)_{4}{ }^{+}:-1189 \mathrm{~kJ} \mathrm{~mol}^{-1} ; 2 \mathrm{x}-594 \mathrm{~kJ} \mathrm{~mol}^{-1}\right)$, as 
shown in Figure 5b. A bit more stable, by $2 \mathrm{~kJ} \mathrm{~mol}^{-1}$, configuration has been found for the linear structure, where only one chlorine atom is shared between magnesium ions, both of them entirely using all available oxygen atoms $\left(\mathrm{Mg}_{2} \mathrm{Cl}_{3}(\mathrm{Gl})_{4}{ }^{+}\right.$: $-1193 \mathrm{~kJ} \mathrm{~mol}^{-1} ; 2 \mathrm{x}-596 \mathrm{~kJ} \mathrm{~mol}^{-1}$ - Figure $\left.5 \mathrm{c}\right)$. A similar situation is observed for $\mathrm{Mg}_{3} \mathrm{Cl}_{4}{ }^{2+}$, eventually resulting in a more linear structure with two additional magnesium cations solvated and one connected to 4 chlorine atoms in the center of cluster $\left(\mathrm{Mg}_{3} \mathrm{Cl}_{4}(\mathrm{G} 1)_{5}^{2+}:-1779 \mathrm{~kJ} \mathrm{~mol}^{-1} ; 3 x-593 \mathrm{~kJ} \mathrm{~mol}^{-1}-\right.$ Figure $\left.\mathrm{S} 4 \mathrm{c}\right)$. Preference toward creation of this kind of motifs in $\mathrm{G1}$ is well-known and it was shown experimentally to prevail even for bigger clusters $\left(\mathrm{Mg}_{4} \mathrm{Cl}_{6}(\mathrm{G1})_{6}{ }^{2+}\right){ }^{[61-63]}$ An analogous structure, with one additional chlorine anion around the central magnesium cation, replacing the $\mathrm{G} 1$ molecule, was found to be the most stable for $\mathrm{Mg}_{3} \mathrm{Cl}_{5}{ }^{+}$ stoichiometry $\left(\mathrm{Mg}_{3} \mathrm{Cl}_{5}(\mathrm{G} 1)_{4}{ }^{+}:-1783 \mathrm{~kJ} \mathrm{~mol}^{-1} ; 3 \mathrm{x}-594 \mathrm{~kJ} \mathrm{~mol}^{-1}-\right.$ Figure S4d). Surprisingly, the pyramidal structure observed in the THF system, is not as preferred $\left(\mathrm{Mg}_{3} \mathrm{Cl}_{5}(\mathrm{G} 1)_{3}{ }^{+}:-1702 \mathrm{~kJ} \mathrm{~mol}^{-1} ; 3 \mathrm{x}-567 \mathrm{~kJ} \mathrm{~mol}^{-}\right.$ $\left.{ }^{1}\right)$; even if the structure requires two sites solvent coordination - ideal for bidentate G1 solvent. A closer look at that structure reveals that the alignment of chlorine ligands in the $\mathrm{Mg}_{3} \mathrm{Cl}_{5}{ }^{+}$framework forces a specific conformation of the glyme chain that is less energetically preferred than the one adopted when only two chlorines surrounds magnesium. This effect is still weak in the case of G1, but becomes stronger and more significant when extending the glyme chain. Dyglime is a good example of this situation. Here there are three oxygen atoms present in the structures, which complicate the cation coordination (too little for full solvation in many cases, and at the same time, the chain gets too long for a convenient accommodation of a few glyme molecules). In principle, that could give rise to less solvated pyramidal structures, where a lower number of available oxygen atoms would be enough for the full saturation of the magnesium coordination shell. However, as our calculations show, the pyramidal structure of $\mathrm{Mg}_{2} \mathrm{Cl}_{3}\left(\mathrm{G}_{2}\right)_{3}{ }^{+}\left(-1181 \mathrm{~kJ} \mathrm{~mol}^{-1} ; 2 \mathrm{x}-590 \mathrm{~kJ} \mathrm{~mol}^{-1}\right)$ shown in Figure $6 \mathrm{a}$ is less preferred than a more linear one with a third glyme molecule being shared between both magnesium cations ($1246 \mathrm{~kJ} \mathrm{~mol}^{-1} ; 2 \mathrm{x}-623 \mathrm{~kJ} \mathrm{~mol}^{-1}$ - Figure 6b). The reason for that is the different conformation of the glyme chain, with tgg triads dominating in the former - forming a disc-like structure; and tgt triads in the latter - a horseshoe-like wrapping around magnesium. Presence of tgt triads has already been shown in literature to be preferred in the coordination of different cations, providing less tension on the glyme chain, thus lowering the energy of the system. ${ }^{[56,64,65]}$ Similarly, this effect causes the preference of $\mathrm{Mg}_{3} \mathrm{Cl}_{4}\left(\mathrm{G}_{2}\right)_{4}{ }^{2+}$ with two glymes solely coordinated to side-Mg cations, and the other two glymes linking the central cations with the side ones (-1689 $\mathrm{kJ} \mathrm{mol}^{-1} ; 3 \mathrm{x}-563 \mathrm{~kJ} \mathrm{~mol}^{-1}-$ Figure S5c). The introduction of an additional chlorine anion to the cluster completely changes the structure, reducing the number of solvent molecules by one and thus increasing the aggregation. The predicted $\mathrm{Mg}_{3} \mathrm{Cl}_{5}(\mathrm{G} 2)_{3}{ }^{+}$structure (-1806 kJ mol${ }^{-1} ; 3 \mathrm{x}-602 \mathrm{~kJ} \mathrm{~mol}^{-1}$ - Figure S5d), represents a compromise between the pyramidal (observed for THF system) and linear (observed for G1 system) structure with each of the cations fully solvated by a single $\mathrm{G} 2$ chain, and coordinating three chlorine anions. Importantly, this structure was found to provide the lowest energy among all the G2-based multimagnesium clusters, whereas the others can be considered less stable, also compared to clusters formed in THF and $\mathrm{G} 1$ environments. 


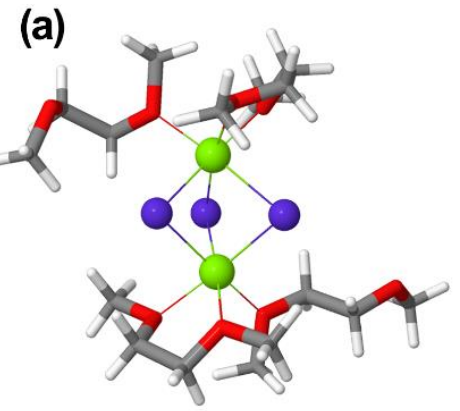

$-1177 \mathrm{~kJ} \mathrm{~mol}^{-1}$

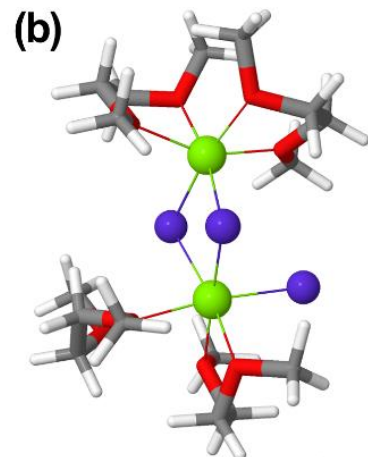

$-1189 \mathrm{~kJ} \mathrm{~mol}^{-1}$

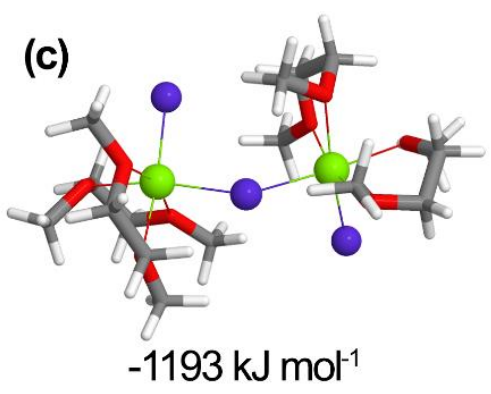

Figure 5. Comparison of different structures found for $\mathrm{Mg}_{2} \mathrm{Cl}_{3}(\mathrm{GI})_{4}{ }^{+}$and their formation energies; colors describe different elements: green - magnesium, violet-chlorine, red-oxygen, grey-carbon, white-hydrogen

(a)

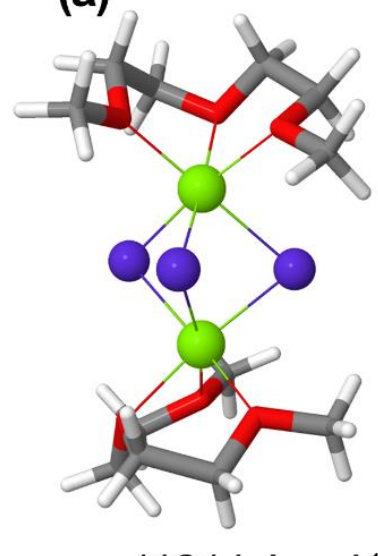

(b)

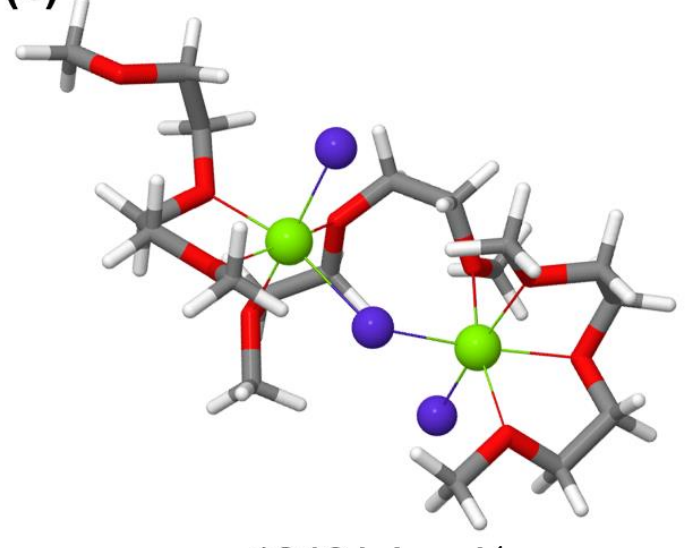

$-1246 \mathrm{~kJ} \mathrm{~mol}^{-1}$

Figure 6. Comparison of different structures found for $\mathrm{Mg}_{2} \mathrm{Cl}_{3}(\mathrm{G} 2)_{3}{ }^{+}$and their formation energies; colors describe different elements: green - magnesium, violet - chlorine, red-oxygen, grey-carbon, white - hydrogen

Further increase of the glyme chain results in a sufficient number of oxygen atoms provided by a single solvent molecule for efficient solvation of the Mg cations in the cluster. Thus, both G3- and G4-based systems are similar, with the same structural motif dominated in all studied stoichiometries: $\mathrm{Mg}^{2+}$ fully coordinated by a single glyme with the addition of two chlorine anions. That leads to structures which (in most of the cases) are analogues to the ones found for G1, presented in Figure S6 and S7. A more complex structure is observed for the $\mathrm{Mg}_{3} \mathrm{Cl}_{4}{ }_{4}^{2+}$ clusters, where the central magnesium atom completes its solvation shell with two oxygen atoms shared from the glymes solvating the terminated $\mathrm{Mg}$ cations. In general, G4 provides better solvation than G3, due to the extra oxygen atom involved, as it can be seen by the lower energies in all G4-containing clusters. 
The summary of the most stable dimers and trimers is presented in Figure 7, which clearly shows the existence of a relationship between the choice of solvent and the structure. THF tends to build more aggregated structures, whereas the chelate nature of the glymes shifts the preference toward more solvated clusters. Among the latter, G2 stands out by forming structures with different motifs than $\mathrm{G} 1$, G3 and G4. It is evidently caused by the number of oxygen atoms in the glyme chain: two (G1) and four (G3) oxygen atoms seems to be prefered for the stabilization of solvated $\mathrm{Mg}_{x} \mathrm{Cl}_{y}$ clusters. Additional oxygen atoms in the case of $\mathrm{G} 4$ gives further stabilization of the structural motif induced by $\mathrm{G} 3$. In contrast, in the case of $\mathrm{G} 2$ there are three oxygen atoms, which are not sufficient for a full solvation in the same manner. In addition the ligand deficit is too small to benefit from additional $\mathrm{G} 2$ molecule forcing the system to create distinct structures. This may explain the reported distinct electrochemical behaviour of G2-based electrolytes, with a lower overpotential for Mg plating. ${ }^{[66]}$ Comparing the free energies per $\mathrm{Mg}^{2+}$ present in the structure, for all of the cases, single charged species have lower energy than that of the doubly charged. However, as mentioned before, the formation of charged species in the $\mathrm{Mg}$ electrolyte is a result of an equilibrium with $\mathrm{Cl}^{-}$accepting acidic species e.g. $\mathrm{AlCl}_{3}$. Such coordination of $\mathrm{Cl}^{-}$is a driving force for the formation of charged species, and has to be considered when comparing the free energies of formation for single and double charged cationic clusters: the latter are more promoted by that process, by ca. $-26 \mathrm{~kJ} \mathrm{~mol}^{-1}$ in the case of $\mathrm{AlCl}_{3}$. Thus, a low difference in free energy, like that observed in $\mathrm{G} 1$ (-593 and $-596 \mathrm{~kJ} \mathrm{~mol}^{-1}$ for $\mathrm{Mg}_{3} \mathrm{Cl}_{4}(\mathrm{G} 1)_{5}{ }^{2+}$ and $\mathrm{Mg}_{2} \mathrm{Cl}_{3}(\mathrm{G} 1)_{4}{ }^{+}$, respectively) indicates a preference for the formation of the $\mathrm{Mg}_{3} \mathrm{Cl}_{4}{ }^{2+}$-stoichiometry complex. Indeed, such structure was found experimentally in G1-based electrolyte by Salama et al. ${ }^{[61]}$ The trimeric structure, $\mathrm{Mg}_{3} \mathrm{Cl}_{5}{ }^{+}$, is also more expected for $\mathrm{G} 2$ than dimeric $\mathrm{Mg}_{2} \mathrm{Cl}_{3}{ }^{+}$, as showing slightly lower energy calculated per magnesium cation, $-602 \mathrm{~kJ} \mathrm{~mol}^{-1}$ for $\mathrm{Mg}_{3} \mathrm{Cl}_{5}(\mathrm{G} 2)_{3}{ }^{+}$. 


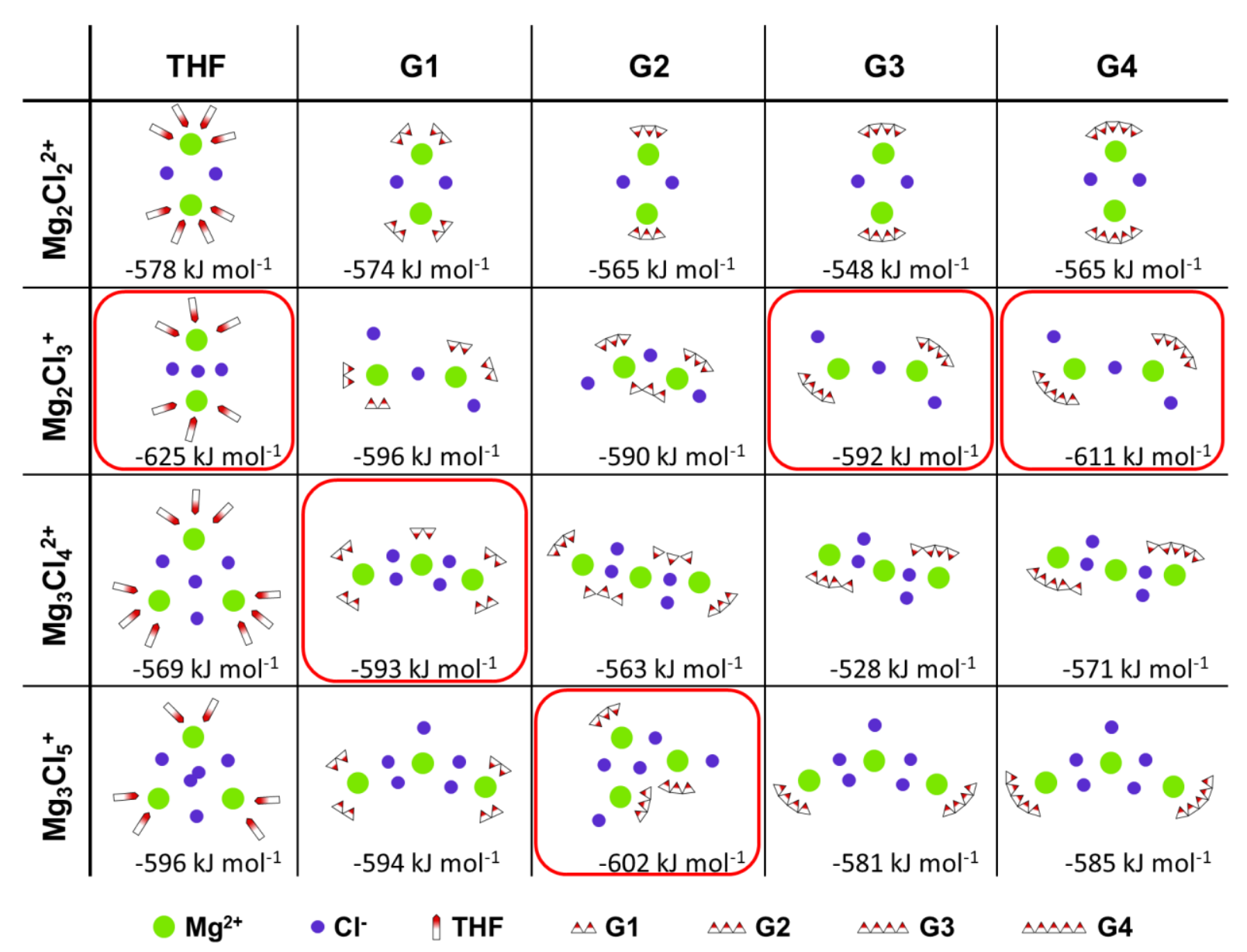

Figure 7. Summary of the most stable multi-magnesium clusters. Values represent the free energies divided by the number of magnesium cations for easier comparison between different stoichiometries; the most expected species for each of the solvent are highlighted. To compare singly and doubly charged clusters, a correction for coordination of $\mathrm{Cl}^{-}$should be applied, assessed to be ca. $-26 \mathrm{~kJ} \mathrm{~mol}^{-1}$ for $\mathrm{AlCl}_{3}$.

Finally, comparing these multiclusters with small, single magnesium complexes, we notice that the former cannot be considered as the most stable in all cases, as seen before for THF-based system by Canepa et al. ${ }^{[28]}$. For most of solvents, $\mathrm{MgCl}\left(\right.$ solvent) ${ }_{x}{ }^{+}$clusters are still more stable than other single charged species, whereas multi-magnesium clusters are thermodynamically preferred in case of doubly charged species. However as the energetic differences are not big, 8-22 $\mathrm{kJ} \mathrm{mol}^{-1}$, larger clusters are still expected to be formed as a result of equilibrium in the electrolyte, and to play an important role during magnesium plating. Their presence, even in small concentration, can significantly affect behaviour at the interfaces, and thus cannot be neglected.

\section{Impact of the electrolyte structure on the electrode processes}

The specific structure of the electrolyte formed as a function of the salt and solvent has a significant impact on the plating/stripping of magnesium, as the coordination environment of $\mathrm{Mg}^{2+}$ affects both the electron transport and the desolvation process. Having established geometries of the most stable monomeric, dimeric, and trimeric structures in ethereal solvents, we looked at these two processes. Two simple descriptors were used to provide a quick overview on the processes that can happen close to the electrode: (i) the desolvation energy - the energy needed to remove $\mathrm{Mg}^{2+}$ from the cluster, (ii) 
and the reduction potential $\left(E_{\text {red }}\right)$ - calculated as the adiabatic electron affinity of the cluster (i.e. the energy gain in the cluster after adding one electron to it). Undoubtedly, the removal of the solvation shell and the electron transfer are processes overlapping during the $\mathrm{Mg}$ plating, requiring a more detailed step-by-step analysis than the one presented here. However, our simplified picture aims to identify trends, allowing analysis of all 30 clusters found.

Observed changes in the desolvation energy clearly indicate easier removal of the solvation shell when increasing the size of the cluster (Figure 8). The presence of $\mathrm{Cl}^{-}$anions reduces the charge density of $\mathrm{Mg}^{2+}$, decreasing the interaction between magnesium cations and solvent molecules. Additionally, breaking the bond between magnesium and chlorine is easier when it involves bridged $\mathrm{Cl}^{-}$anions. In that case, the charge density donated by anion can be easily transferred from one cation to another, facilitating the removal of magnesium from the cluster structure. That explains the much higher decrease in desolvation energy, as observed for the THF cluster and $\mathrm{Mg}_{3} \mathrm{Cl}_{5}(\mathrm{G} 1)_{4}{ }^{+}$- all characterized by high aggregation levels. In general, glymes form more solvated structures that do not allow fully taking advantage of beneficial $\mathrm{Mg}-\mathrm{Cl}$ structures. Nonetheless, their interaction with magnesium cations is weaker, resulting in lower desolvation energies for all of the structures.

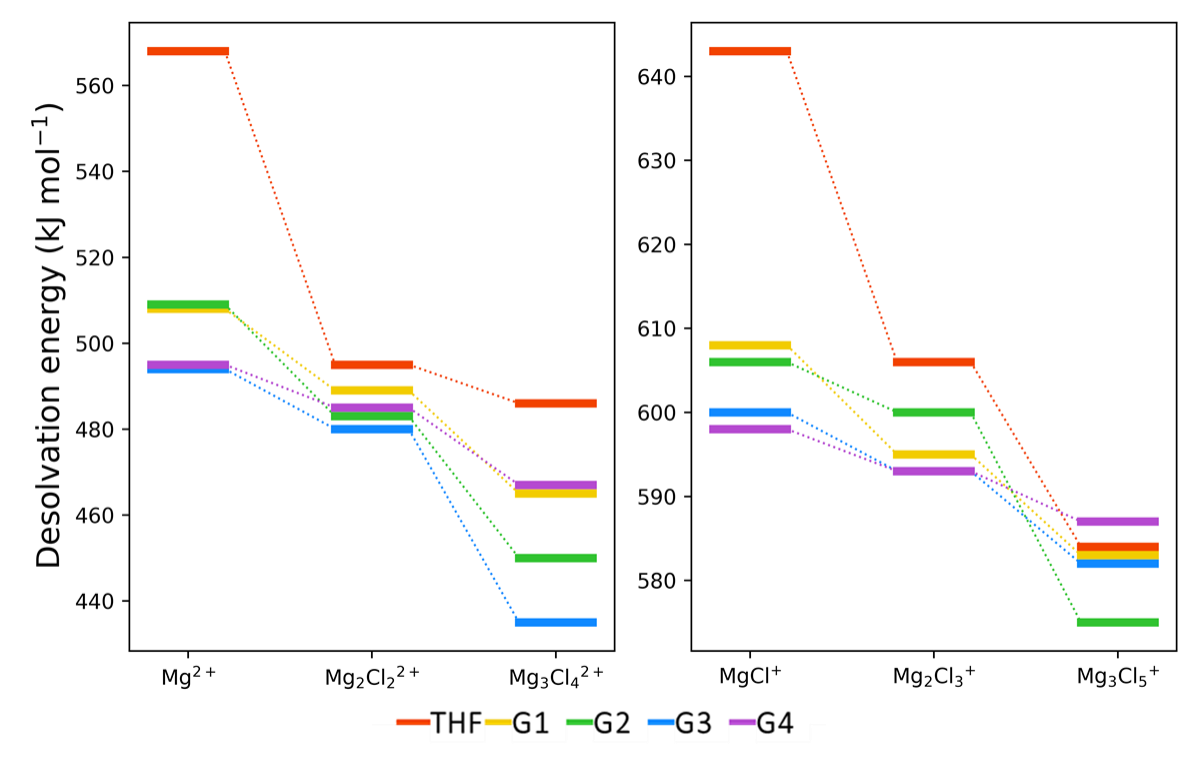

Figure 8. Desolvation energy of different complexes, calculated as energy of $\mathrm{Mg}^{2+}$ removal from the complex.

The opposite trend when increasing the cluster size, was found when analysing electron transfer processes. Larger clusters are less prone to accept an extra electron, observed as a lower reduction potential (Figure 9). That again is the result of some shift of electron density from chlorine to magnesium, which hinders the stabilization of the added electron. Looking at different structures of the same $\mathrm{Mg}_{x} \mathrm{Cl}_{y}$ stoichiometry, another relationship is observed: the presence of $\mathrm{Cl}^{-}$linked to many magnesium cations is beneficial, as their electron density can be moved from one magnesium center to another. That explains why the highest $E_{\text {red }}$ were found for the THF-based clusters - characterized by pyramidal structures. Glymes, providing a better-adapting structure for the solvation, shows a lower reduction potential (higher plating overpotentials) without a clear pattern regarding the influence of the chain length or cluster structure. Above all, the observed levels of the reduction potentials are much below the expected $0 \mathrm{~V}$ vs. $\mathrm{Mg}$, which indicates that at least partial removal of the solvation shell is happening prior to electron transfer. The reduction potential of the bare $\mathrm{Mg}_{2} \mathrm{Cl}_{3}{ }^{+}$structure was calculated to be $+0.63 \mathrm{~V}$ vs. $\mathrm{Mg}$, demonstrating the huge impact of solvation shell on the reduction potential. 


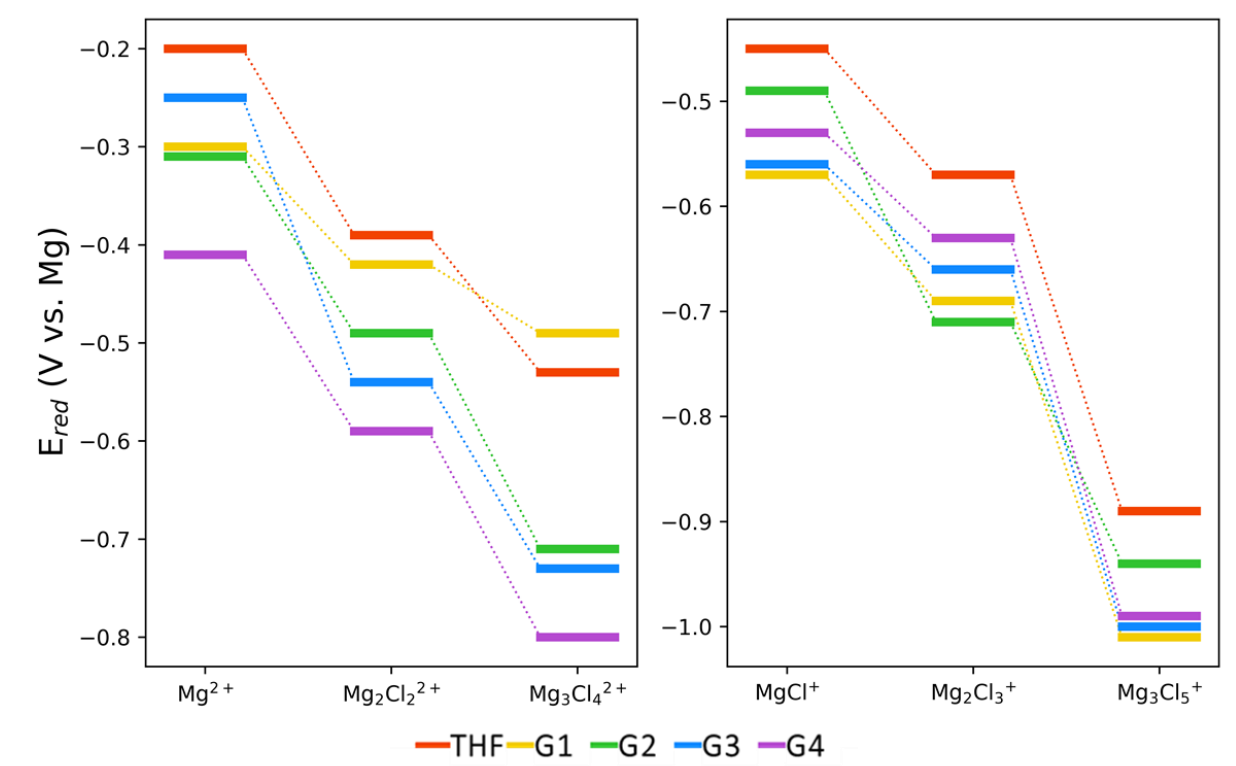

Figure 9. One-electron reduction potentials $\left(E_{\text {red }}\right)$ of different complexes.

\section{Conclusions}

Many properties of the recently reported electrolytes are limited by the solvent. Therefore, development of improved multivalent battery electrolytes may benefit from directing more focus towards the solvent component of the electrolyte. The analysis presented here, provides a detailed picture on the creation of magnesium chloride complexes in ethereal systems.

The comparison of THF with multi-dentate linear glymes indicates that the ability of the former to coordinate ions is limited by the bulkier structure of the ring, leading to more aggregated structures. Glymes, on the other hand, are able to effectively adjust their conformation and maximize interactions between magnesium and the solvent. Additionally, the multidentate nature of the glymes causes a smaller loss in entropy upon the clusters formation, as compared to the monodentate THF. All of that has consequences for both the structures of the clusters formed and their activity at the electrode. THF favours structures with a smaller degree of solvation (a lower number of solvent oxygen atoms in the coordination of magnesium), while more linear structures are induced by most of the glymes, allowing for higher solvation. However, the analysis shows some exception - diglyme (G2), which in some cases tends to create highly aggregated structures, e.g. $\mathrm{Mg}_{3} \mathrm{Cl}_{5}\left(\mathrm{G}_{2}\right)_{3}{ }^{+}$, that is found to be caused by mismatching number of oxygen atoms (too low to stabilize solvated magnesium cations using one glyme chain, and too high to employ two glyme chains). Although looking at the energetics, simple clusters are predominant in the bulk of these electrolytes, presence of more complicated aggregates is anticipated due to relatively small energy difference. These larger aggregates, formed as a result of equilibrium, are believed to be crucial for reversible reactions at electrodes. The increase in the cluster size leads to the easier removal of the solvation shell. However, larger cluster size and higher solvation were found to be responsible for the larger overpotential for the electron transfer, and thus for magnesium plating. This may explain the success of THF-based electrolytes, which prefers to form smaller and highly aggregated complexes. Among the glymes, the similar behaviour was found for diglyme (G2), leaving it as the most promising. Taking into account that its boiling point is $100^{\circ} \mathrm{C}$ higher than that of THF, diglyme can be seen as a less volatile alternative to THF in magnesium batteries.

\section{Acknowledgements}


All calculations were carried out at the Wrocław Centre for Networking and Supercomputing, Grant 346. We acknowledge the funding from the European Union's Horizon 2020 research and innovation programme under grant agreement No 824066 (E-MAGIC).

\section{References}

[1] A. Ponrouch, J. Bitenc, R. Dominko, N. Lindahl, P. Johansson, M. R. Palacin, Energy Storage Materials 2019, 20, 253-262.

[2] M. Walter, M. V. Kovalenko, K. V. Kravchyk, New J. Chem. 2020, 44, 1677-1683.

[3] H. D. Yoo, I. Shterenberg, Y. Gofer, G. Gershinsky, N. Pour, D. Aurbach, Energy Environ. Sci. 2013, 6, 2265-2279.

[4] D. Aurbach, Z. Lu, A. Schechter, Y. Gofer, H. Gizbar, R. Turgeman, Y. Cohen, M. Moshkovich, E. Levi, Nature 2000, 407, 724-727.

[5] R. Attias, M. Salama, B. Hirsch, Y. Goffer, D. Aurbach, Joule 2019, 3, 27-52.

[6] J. Muldoon, C. B. Bucur, A. G. Oliver, T. Sugimoto, M. Matsui, H. S. Kim, G. D. Allred, J. Zajicek, Y. Kotani, Energy Environ. Sci. 2012, 5, 5941-5950.

[7] N. Sa, B. Pan, A. Saha-Shah, A. A. Hubaud, J. T. Vaughey, L. A. Baker, C. Liao, A. K. Burrell, ACS Appl. Mater. Interfaces 2016, 8, 16002-16008.

[8] R. Dugas, J. D. Forero-Saboya, A. Ponrouch, Chem. Mater. 2019, 31, 8613-8628.

[9] J. Muldoon, C. B. Bucur, T. Gregory, Chem. Rev. 2014, 114, 11683-11720.

[10] J. D. Forero-Saboya, E. Marchante, R. B. Araujo, D. Monti, P. Johansson, A. Ponrouch, J. Phys. Chem. C 2019, 123, 29524-29532.

[11] R. Schwarz, M. Pejic, P. Fischer, M. Marinaro, L. Jörissen, M. Wachtler, Angewandte Chemie International Edition 2016, 55, 14958-14962.

[12] R. Jay, A. W. Tomich, J. Zhang, Y. Zhao, A. De Gorostiza, V. Lavallo, J. Guo, ACS Appl. Mater. Interfaces 2019, 11, 11414-11420.

[13] J. T. Herb, C. A. Nist-Lund, C. B. Arnold, ACS Energy Lett. 2016, 1, 1227-1232.

[14] Z. Zhao-Karger, M. E. G. Bardaji, O. Fuhr, M. Fichtner, J. Mater. Chem. A 2017, 5, 10815-10820.

[15] D. Aurbach, H. Gizbar, A. Schechter, O. Chusid, H. E. Gottlieb, Y. Gofer, I. Goldberg, J. Electrochem. Soc. 2001, 149, A115.

[16] I. Shterenberg, M. Salama, H. D. Yoo, Y. Gofer, J.-B. Park, Y.-K. Sun, D. Aurbach, J. Electrochem. Soc. 2015, 162, A7118.

[17] B. Pan, J. Huang, M. He, S. M. Brombosz, J. T. Vaughey, L. Zhang, A. K. Burrell, Z. Zhang, C. Liao, ChemSusChem 2016, 9, 595-599.

[18] R. Attias, M. S. Chae, B. Dlugatch, M. Oliel, Y. Goffer, D. Aurbach, ACS Catal. 2020, 7773-7784.

[19] C. J. Barile, R. G. Nuzzo, A. A. Gewirth, J. Phys. Chem. C 2015, 119, 13524-13534.

[20] Z. Lu, A. Schechter, M. Moshkovich, D. Aurbach, Journal of Electroanalytical Chemistry 1999, $466,203-217$.

[21] J. Self, N. T. Hahn, K. D. Fong, S. A. McClary, K. R. Zavadil, K. A. Persson, J. Phys. Chem. Lett. 2020, 11, 2046-2052.

[22] Y. Cheng, R. M. Stolley, K. S. Han, Y. Shao, B. W. Arey, N. M. Washton, K. T. Mueller, M. L. Helm, V. L. Sprenkle, J. Liu, G. Li, Phys. Chem. Chem. Phys. 2015, 17, 13307-13314.

[23] F. Tuerxun, Y. Abulizi, Y. NuLi, S. Su, J. Yang, J. Wang, Journal of Power Sources 2015, 276, 255261.

[24] C. Zhang, A. Yamazaki, J. Murai, J.-W. Park, T. Mandai, K. Ueno, K. Dokko, M. Watanabe, J. Phys. Chem. C 2014, 118, 17362-17373.

[25] D. Morales, R. E. Ruther, J. Nanda, S. Greenbaum, Electrochimica Acta 2019, 304, 239-245.

[26] G. Horwitz, M. Factorovich, J. Rodriguez, D. Laria, H. R. Corti, ACS Omega 2018, 3, 1120511215.

[27] J. B. Moss, L. Zhang, K. V. Nielson, Y. Bi, C. Wu, S. Scheiner, T. L. Liu, Batteries \& Supercaps 2019, $2,792-800$. 
[28] P. Canepa, S. Jayaraman, L. Cheng, N. N. Rajput, W. D. Richards, G. S. Gautam, L. A. Curtiss, K. A. Persson, G. Ceder, Energy Environ. Sci. 2015, 8, 3718-3730.

[29] M. J. Frisch, G. W. Trucks, H. B. Schlegel, G. E. Scuseria, M. A. Robb, J. R. Cheeseman, G. Scalmani, V. Barone, B. Mennucci, G. A. Petersson, H. Nakatsuji, M. Caricato, X. Li, H. P. Hratchian, A. F. Izmaylov, J. Bloino, G. Zheng, J. L. Sonnenberg, M. Hada, M. Ehara, K. Toyota, R. Fukuda, J. Hasegawa, M. Ishida, T. Nakajima, Y. Honda, O. Kitao, H. Nakai, T. Vreven, J. A. Montgomery Jr., J. E. Peralta, F. Ogliaro, M. J. Bearpark, J. Heyd, E. N. Brothers, K. N. Kudin, V. N. Staroverov, R. Kobayashi, J. Normand, K. Raghavachari, A. P. Rendell, J. C. Burant, S. S. Iyengar, J. Tomasi, M. Cossi, N. Rega, N. J. Millam, M. Klene, J. E. Knox, J. B. Cross, V. Bakken, C. Adamo, J. Jaramillo, R. Gomperts, R. E. Stratmann, O. Yazyev, A. J. Austin, R. Cammi, C. Pomelli, J. W. Ochterski, R. L. Martin, K. Morokuma, V. G. Zakrzewski, G. A. Voth, P. Salvador, J. J.

Dannenberg, S. Dapprich, A. D. Daniels, Ö. Farkas, J. B. Foresman, J. V. Ortiz, J. Cioslowski, D. J. Fox, Gaussian 16, Revision B.01, Gaussian, Inc., Wallingford, CT, USA, 2016.

[30] J. J. P. Stewart, J Mol Model 2013, 19, 1-32.

[31] R. Krishnan, J. S. Binkley, R. Seeger, J. A. Pople, J. Chem. Phys. 1980, 72, 650-654.

[32] Y. Zhao, D. G. Truhlar, Theor Chem Account 2008, 120, 215-241.

[33] P. Jankowski, W. Wieczorek, P. Johansson, J Mol Model 2017, 23, 6.

[34] A. V. Marenich, C. J. Cramer, D. G. Truhlar, J. Phys. Chem. B 2009, 113, 6378-6396.

[35] C. F. Riadigos, R. Iglesias, M. A. Rivas, T. P. Iglesias, The Journal of Chemical Thermodynamics 2011, 43, 275-283.

[36] S. Trasatti, Pure and Applied Chemistry 2009, 58, 955-966.

[37] V. Barone, M. Cossi, J. Phys. Chem. A 1998, 102, 1995-2001.

[38] H. S. Kim, T. S. Arthur, G. D. Allred, J. Zajicek, J. G. Newman, A. E. Rodnyansky, A. G. Oliver, W. C. Boggess, J. Muldoon, Nature Communications 2011, 2, 1-6.

[39] Y. Guo, F. Zhang, J. Yang, F. Wang, Y. NuLi, S. Hirano, Energy Environ. Sci. 2012, 5, 9100-9106.

[40] K. A. See, K. W. Chapman, L. Zhu, K. M. Wiaderek, O. J. Borkiewicz, C. J. Barile, P. J. Chupas, A. A. Gewirth, J. Am. Chem. Soc. 2016, 138, 328-337.

[41] K. A. See, Y.-M. Liu, Y. Ha, C. J. Barile, A. A. Gewirth, ACS Appl. Mater. Interfaces 2017, 9, 3572935739.

[42] P. Sobota, T. Pluzinski, J. Utko, T. Lis, Inorg. Chem. 1989, 28, 2217-2219.

[43] T. Liu, Y. Shao, G. Li, M. Gu, J. Hu, S. Xu, Z. Nie, X. Chen, C. Wang, J. Liu, J. Mater. Chem. A 2014, 2, 3430-3438.

[44] J. Muldoon, C. B. Bucur, A. G. Oliver, J. Zajicek, G. D. Allred, W. C. Boggess, Energy Environ. Sci. 2013, 6, 482-487.

[45] N. Pour, Y. Gofer, D. T. Major, D. Aurbach, J. Am. Chem. Soc. 2011, 133, 6270-6278.

[46] W. Li, S. Cheng, J. Wang, Y. Qiu, Z. Zheng, H. Lin, S. Nanda, Q. Ma, Y. Xu, F. Ye, M. Liu, L. Zhou, Y. Zhang, Angewandte Chemie International Edition 2016, 55, 6406-6410.

[47] M. H. Al-Afyouni, K. L. Fillman, W. W. Brennessel, M. L. Neidig, J. Am. Chem. Soc. 2014, 136, 15457-15460.

[48] P. Sobota, T. Płuziński, T. Lis, Zeitschrift für anorganische und allgemeine Chemie 1986, 533, 215-224.

[49] P. Kubisiak, A. Eilmes, J. Phys. Chem. C 2018, 122, 12615-12622.

[50] O. Tutusaus, R. Mohtadi, T. S. Arthur, F. Mizuno, E. G. Nelson, Y. V. Sevryugina, Angewandte Chemie International Edition 2015, 54, 7900-7904.

[51] Z. Zhao-Karger, J. E. Mueller, X. Zhao, O. Fuhr, T. Jacob, M. Fichtner, RSC Adv. 2014, 4, 2692426927.

[52] M. Vestergren, J. Eriksson, M. Håkansson, Journal of Organometallic Chemistry 2003, 681, 215224.

[53] T. Liu, J. T. Cox, D. Hu, X. Deng, J. Hu, M. Y. Hu, J. Xiao, Y. Shao, K. Tang, J. Liu, Chem. Commun. 2015, 51, 2312-2315.

[54] S. Sakamoto, T. Imamoto, K. Yamaguchi, Org. Lett. 2001, 3, 1793-1795.

[55] L. F. Wan, D. Prendergast, J. Am. Chem. Soc. 2014, 136, 14456-14464. 
[56] P. Johansson, J. Grondin, J.-C. Lassègues, J. Phys. Chem. A 2010, 114, 10700-10705.

[57] P. Johansson, Polymer 2001, 42, 4367-4373.

[58] T. Mandai, K. Tatesaka, K. Soh, H. Masu, A. Choudhary, Y. Tateyama, R. Ise, H. Imai, T. Takeguchi, K. Kanamura, Phys. Chem. Chem. Phys. 2019, 21, 12100-12111.

[59] S. Terada, T. Mandai, S. Suzuki, S. Tsuzuki, K. Watanabe, Y. Kamei, K. Ueno, K. Dokko, M. Watanabe, J. Phys. Chem. C 2016, 120, 1353-1365.

[60] L. C. Merrill, J. L. Schaefer, Chem. Mater. 2018, 30, 3971-3974.

[61] M. Salama, I. Shterenberg, L. J.W. Shimon, K. Keinan-Adamsky, M. Afri, Y. Gofer, D. Aurbach, J. Phys. Chem. C 2017, 121, 24909-24918.

[62] V. H. Nissinen, I. O. Koshevoy, T. T. Pakkanen, Dalton Trans. 2017, 46, 4452-4460.

[63] A. Du, Z. Zhang, H. Qu, Z. Cui, L. Qiao, L. Wang, J. Chai, T. Lu, S. Dong, T. Dong, H. Xu, X. Zhou, G. Cui, Energy Environ. Sci. 2017, 10, 2616-2625.

[64] Y.-C. Guo, C. Cai, Y.-H. Zhang, AIP Advances 2018, 8, 055308.

[65] P. Jankowski, M. Dranka, G. Z. Żukowska, J. Phys. Chem. C 2015, 119, 10247-10254.

[66] Y. Shao, T. Liu, G. Li, M. Gu, Z. Nie, M. Engelhard, J. Xiao, D. Lv, C. Wang, J.-G. Zhang, J. Liu, Scientific Reports 2013, 3, 3130. 